\title{
Phytochemical Screening and Characterization of Olean-18-ene Type Triterpeniod from the Roots of Lantana camara
}

\author{
Kebede Taye $^{1^{\star}}$, Kibret Fikadu ${ }^{2}$, Fikre Mammo $^{2}$ and Milkyas Endale ${ }^{2^{\star}}$ \\ ${ }^{1}$ Department of Chemistry, College of Natural and Computational Sciences, Mekelle University, \\ P.O. Box: 231, Mekelle, Ethiopia \\ ${ }^{2}$ Department of Chemistry, College of Natural and Computational Science, Hawassa University,
} P.O. Box: 05, Hawassa, Ethiopia

\begin{tabular}{|c|c|}
\hline Abstract & Article Information \\
\hline $\begin{array}{l}\text { Lantana camara, commonly called wild or red sage or sleeper weed is the most } \\
\text { widely spread species of the genus Lantana traditionally used to treat various } \\
\text { diseases such as diarrhea, fever, and stomachache. It has also been reported to } \\
\text { show antifungal, antiproliferative, insecticidal, antimicrobial and germicidal activity. } \\
\text { Phytochemical screening of the methanol extract revealed the presence of } \\
\text { flavanoids, terpenes, saponins and the absence of anthraquinones and alkaloids. } \\
\text { Silica gel column chromatographic separation of the methanol root extract yielded } \\
\text { an olean-18-ene type triterpene. Complete characterization of the isolated } \\
\text { compound was done using spectroscopic techniques (UV-Vis, IR, }{ }^{1} \mathrm{H}-\mathrm{NMR},{ }^{13} \mathrm{C}- \\
\text { NMR, DEPT-135, COSY, HMBC and HSQC). }\end{array}$ & $\begin{array}{l}\text { Article History: } \\
\text { Received : 12-02-2015 } \\
\text { Revised : 23-03-2015 } \\
\text { Accepted : 24-03-2015 } \\
\text { Keywords: } \\
\text { Lantana camara } \\
\text { Terpene } \\
\text { Olean-18-ene type triterpene } \\
{ }^{*} \text { Corresponding Authors: } \\
\text { Milkyas Endale } \\
\text { E-Mail: milkyasendale@yahoo.com } \\
\text { Kebede Taye } \\
\text { E-Mail: kebetila@gmail.com }\end{array}$ \\
\hline
\end{tabular}

\section{INTRODUCTION}

Lantana camara, commonly called wild sage or sleeper weed is the most widely spread species of the genus Lantana. The root system is very strong with a main taproot and a mat of many shallow side roots (Sankaran, 2007; Ross, 1999) It is one of the traditional medicinal plants used in Ethiopia and other part of the world for treatment of various diseases such as diarrhea, fever (Fisseha et al., 2009) and stomachache (Nayak et al., 2008), The plant also showed antifungal (Tripathi and Shukla, 2002 and Kumar et al., 2006), antiproliferative (Nagao et al., 2002), insecticidal, antimicrobial activities (Rajakaruna et al., 2002) and germicidal activities (Ghisalberti, 2005). The powdered root in milk and tea prepared from the leaves and flowers, locally called "Yewef Kolo" (Amharic), protects against fever and cold (Mesfin et al., 2009). Earlier phytochemical screening works on the leaf, flower and aerial parts of $L$. camara revealed the presence of terpenoids, alkaloids, steroids (Ganjewala et al., 2009; Singh et al., 1991; Singh et al., 1990), Lantalonic acid, lantic acid, lupeol derivatives, camarinic acid, camaric acid, camarilic acid and related series of pentacyclic triterpenoids (John et al., 1983a; John et al., 1983b). In East Africa, the genus Lantana is known to harbour tsetse fly (Glossina spp.), the vector of African sleeping sickness (Leak, 1999). Despite the wide use of the genus traditionally, there are no phytochemical studies reported on $L$. camara from Ethiopian flora. We hereby present a comprehensive phytochemial analysis of the methanol root extract of $L$. camara with a complete NMR characterization of one oleanene-18-type triterpene.

\section{MATERIALS AND METHODS}

\section{Instrumentation}

Melting point was recorded by Mettler Toledo apparatus, Type FP62, and it was uncorrected. Column chromatographic isolation was carried out on silica gel (230-400 mesh size, Merck). Thin layer chromatography was done on silica gel $60 \mathrm{~F}-254,0.2 \mathrm{~mm}$ thick layer on aluminum sheets for detection of spots. The UV-Vis spectrum was recorded on UNICAM UV-300 double beam spectrophotometer using $\mathrm{CHCl}_{3}$ as internal standard. The IR absorption spectrum was determined by Shimadzu 440 instrument using $\mathrm{KBr}$ disk in the range of $500-4000 \mathrm{~cm}^{-1}$. The ${ }^{1} \mathrm{H}$ NMR and ${ }^{13} \mathrm{C}$ NMR spectra were recorded using Bruker Avance $400 \mathrm{MHz}$ spectrometer using TMS as internal standard. Chemical shift values for all NMR data are reported in parts per million (ppm) relative to internal standard. All the chemicals used in this study were analytical grade.

\section{Plant Material Collection and Preparation}

The roots of $L$. camara were collected from Wonago, Ethiopia. The plant material was identified by Dr. Ensermu Kelbessa, Department of Biology, Addis Ababa University (AAU) and a voucher specimen was deposited at National Herbarium of Ethiopia, Addis Ababa University, Ethiopia. The collected root part of $L$. camara was dried and grinded in to powder using mortar and was made ready for further analysis. 


\section{Preparation of Crude Methanol Extract}

The grounded $(0.3 \mathrm{Kg})$ root of $L$. camara was soaked in $650 \mathrm{~mL}$ of $n$-hexane for $24 \times 2 \mathrm{hr}$ with occasional shaking and filtering to remove the fat contents. After filtration, the marc left was further soaked in $650 \mathrm{~mL}$ of methanol $(98.6$ $\%)$ for $(24 \times 3 \mathrm{hr})$. The methanol extract was then filtered and concentrated using Rotary Evaporator at $40^{\circ} \mathrm{C}$, air dried and weighted to yield $30.6 \mathrm{~g}(14.3 \%)$ brownish crude extract.

\section{Isolation and Purification of Compounds}

$21 \mathrm{~g}$ of the brownish methanol extract was subjected to silica gel column chromatographic separation $(150 \mathrm{~g}$ silica gel) and eluted with increasing gradient of ethyl acetate in petroleum ether. A total of 41 fractions (each $30 \mathrm{~mL}$ ) were collected. The constituent profile of each fraction was monitored by TLC ( $40 \%$ ethyl acetate in petroleum ether) and visualized under UV-Vis light ( $\lambda_{\max } 254$ and $\left.366 \mathrm{~nm}\right)$. Fractions 17-22 were combined based on their TLC profile and was further purified by column chromatography (eluent: increasing gradient of ethyl acetate in petroleum ether). A total of 11 fractions were collected. Fractions 811 were combined and a pale yellow precipitate was obtained. This precipitate was further washed with $n$ hexane till it gives clear spot on TLC (M.pt: $263.1{ }^{\circ} \mathrm{C}$, $54.8 \mathrm{mg}$ ).

\section{Preliminary phytochemical Screening}

Preliminary screening tests were performed for detection of common secondary metabolites in the methanol extract of roots of L.camara using different reagents and analytical procedures.

\section{Test for alkaloids}

$300 \mathrm{mg}$ of the crude extract was mixed with $2 \mathrm{~mL}$ of concentrated hydrochloric acid. The mixture was then filtered and mixed with small amount of amyl alcohol at room temperature [Ganjewala et al, 2009]. The mixture was kept for observation of the color resulted from the alcoholic layer.

\section{Test for Flavonoids}

$0.2 \mathrm{~g}$ of methanol extract was dissolved in small amount of dilute $\mathrm{NaOH}$ and concentrated $\mathrm{HCl}(3 \mathrm{~mL})$ was added [Farnsworth, 1996]. A yellow solution that turns to colorless was inspected.

\section{Test for Terpenes}

$0.25 \mathrm{~g}$ of methanol extract was mixed with $2 \mathrm{~mL}$ of $\mathrm{CHCl}_{3}$ and $30 \mathrm{~mL}$ of concentrated $\mathrm{H}_{2} \mathrm{SO}_{4}$ was added carefully to form a layer [Debjyoti, 1995]. Reddish-brown coloration of the interface was inspected.

\section{Test for Tannins}

Small quantity of the methanol extract was mixed with water and heated on water bath. The mixture was filtered and small amount of solid $\mathrm{FeCl}_{3}$ was added to the filtrate [Sofowora, 1982]. Dark-green solution was inspected.

\section{Test for Anthraquinones}

$0.5 \mathrm{~g}$ of the methanol extract was boiled with concentrated hydrochloric acid for few minutes in water bath and filtered. The filtrate was allowed to cool and equal volume of $\mathrm{CHCl}_{3}$ was added to it. Few drops of ammonia were added to the mixture and heated in water bath. Formation of rose-pink color was inspected [Sofowora, 1982].

\section{Test for Saponins}

$0.2 \mathrm{~g}$ of the methanol extract was shaken with $5 \mathrm{~mL}$ of distilled water for 30 minutes and then heated to boil. Appearance of creaming miss of small bubbles (frothing) was inspected [Farnsworth, 1996].

\section{RESULTS AND DISCUSSIONS}

\section{Preliminary Phytochemical Screening}

Preliminary phytochemical screening of the methanol extract revealed the presence of terpenoids, flavonoids and saponins whereas alkaloids, tannins and anthraquinones were absent (Table 1).

Table 1: Summary of phytochemical screening tests of the methanol extract

\begin{tabular}{ll}
\hline Plant constituent & Present/absent \\
\hline Alkaloids & - \\
Flavonoids & + \\
Terpenes & + \\
Tannins & - \\
Saponins & + \\
Anthraquinones & - \\
\hline ce of plant constituent, (+) presence of plant constituent
\end{tabular}

(-) Absence of plant constituent, (+) presence of plant constituent

\section{Spectroscopic Analysis}

A broad IR absorption band at $3381.95 \mathrm{~cm}^{-1}$ indicates the existence of hydroxyl group. The absorption band at $1690 \mathrm{~cm}^{-1}$ is attributed to carbonyl group of an ester moiety. The absorption bands observed at $1450 \mathrm{~cm}^{-1}$ and $1270.04 \mathrm{~cm}^{-1}$ are attributed to an olefinic system and C-O stretching vibration of an ester moiety, respectively. Furthermore, the IR absorptions at $2922.92 \mathrm{~cm}^{-1}$ and $3010 \mathrm{~cm}^{-1}$ suggest $\mathrm{sp}^{3} \mathrm{C}-\mathrm{H}$ stretching and $\mathrm{sp}^{2} \mathrm{C}-\mathrm{H}$ stretching vibrations, respectively. The UV spectrum showed characteristic absorption bands for ester carbonyl moiety and alkene double bond at $\lambda_{\max } 263.24$ and 210.14 , respectively.

The ${ }^{1} \mathrm{H}$ NMR spectrum revealed the existence of olefinic proton at $\delta 5.30(1 \mathrm{H}, s, \mathrm{H}-19)$. This peak, being singlet, indicated the absence of proton(s) on the adjacent carbon atom(s) suggesting the presence of adjacent $\mathrm{sp}^{2}$ quaternary carbon. A broad singlet proton at $\delta 3.90$ indicate hydroxyl group and the presence peak at $\delta 3.20$ $(1 \mathrm{H}, d d, \mathrm{H}-3)$ revealed the existence of a methine proton bearing a hydroxyl group. The ${ }^{1} \mathrm{H}$ NMR spectrum showed signals due to seven methyl protons; $\delta 0.65,0.70,0.80$, $0.95,1.00,1.05,1.10$ and 1.25 each being singlet and integrated for three hydrogens. Chemical shift values in between $\delta 1.4-2.30$ with multiplet multiplicity showed the existence of methylene protons. The presence of a triplet at $\delta 1.75(3 \mathrm{H}, t)$ suggest existence of methyl protons with adjacent methylene protons on the adjacent carbon atom (H-2',3', Table 2). The ${ }^{13} \mathrm{C}$ NMR spectrum revealed a total of 35 well resolved carbon peaks, of which one of them at $\delta 79.1$ (C-3) overlapped with the $\mathrm{CDCl}_{3}$ peaks. The presence of ten methyl groups, five methine groups (of which one of them is olefinic (C-19), eleven methylene groups and nine quaternary carbon atoms are all evident from the ${ }^{13} \mathrm{C}$ NMR spectrum. A pair of signals at $\delta 122.5$ (C-19) and $\delta 143.6(\mathrm{C}-18)$ belongs to olefinic carbons. Furthermore, the ${ }^{13} \mathrm{C}$ NMR supported the existence of ester carbonyl carbon at $\delta 183.8(\mathrm{C}-28)$ and hydroxyl bearing methane carbon at $\delta 79.0$ (C-3) (Table 2).

The COSY spectrum supported correlations between $\mathrm{H}_{1} \leftrightarrow \mathrm{H}_{2}, \mathrm{H}_{5} \leftrightarrow \mathrm{H}_{6}, \mathrm{H}_{9} \leftrightarrow \mathrm{H}_{11}$ and $\mathrm{H}_{12} \leftrightarrow \mathrm{H}_{13}$ (Table 2). The HSQC spectrum suggested significant direct connectivity 
Kebede Tayeet alo,

between $\mathrm{C}-5$ and $\mathrm{H}-5, \mathrm{C}-9$ and $\mathrm{H}-9, \mathrm{C}-13$ and $\mathrm{H}-13$, and $\mathrm{C}-27$ and $\mathrm{H}-27$ (Table 2). The gHMBC spectrum showed correlations between $\mathrm{H}-24$ and $\mathrm{C}-5$, correlations between $\mathrm{H}-6$ and carbon $\mathrm{C}-5$, and a long range correlation between $\mathrm{H}-6$ to a quaternary carbon resonating at $\delta 38.74$ (C-8). The position of the double bond at C-18,19 was evident from the HMBC correlations of olefinic proton at $\delta 5.30$ with carbons at $\delta 45.87$ (C-13), $\delta 143.59$ (C-18) and 47.45 (C-17). The linkage of the acyl group a quaternary carbon at $\mathrm{C}-17$ was further supported by the HMBC correlation between methylene protons at $\delta 1.80(\mathrm{H}-16)$ and ester carbonyl carbon at $\delta 183.79$ (C-28). The HMBC spectrum also indicated correlations of the proton $\delta 1.55$ $(\mathrm{H}-22)$ with quaternary carbon at $\delta 30.67$ (C-20); methylene at $\delta 1.45(\mathrm{H}-1)$ with carbon at $\delta 79.04(\mathrm{C}-3)$; and methine proton at $\delta 2.00(\mathrm{H}-13)$ with methyl carbon at $\delta$ 25.94 (C-27) (Table 2, Figure 1).

Based on the above spectral data, a triterpenoid skeleton is clearly evident having a hydroxyl group, an acyl moiety and olefinic protons constituting a total of 35 carbons. In agreement with the literature data, the spectral data of the compound is in good correlation with compounds having olean-18-ene class of triterpenoids bearing hydroxyl at C-3 and olefinic group at C-18,19. In support of this, signals from ${ }^{13} \mathrm{C}$ NMR observed at $\delta 122.50$ and $\delta 143.59$ due to olefinic carbons, at $\delta 183.79$ due to ester moiety and $\delta 79.04$ due to an oxygenated
Sci. Technol. Arts Res. J., Jan-March 2015, 4(1): 91-94

methine carbon, combined with signals observed in the ${ }^{1} \mathrm{H}$ NMR spectrum all justify a typical structural feature of pentacyclic triterpene of oleanane type. Thus, based on the observed spectral data (Table 2) and extensive comparison with literature, the following oleane-18-ene triterpene was proposed (Figure 1). This class of triterpenes have also been a focus by several researchers and proved to have cytotoxic activity [Rios et al, 2001], antitumor activity [Chiang et al., 2003] and a range of biological and pharmacological activities as reviewed by Hua et al. (2006).

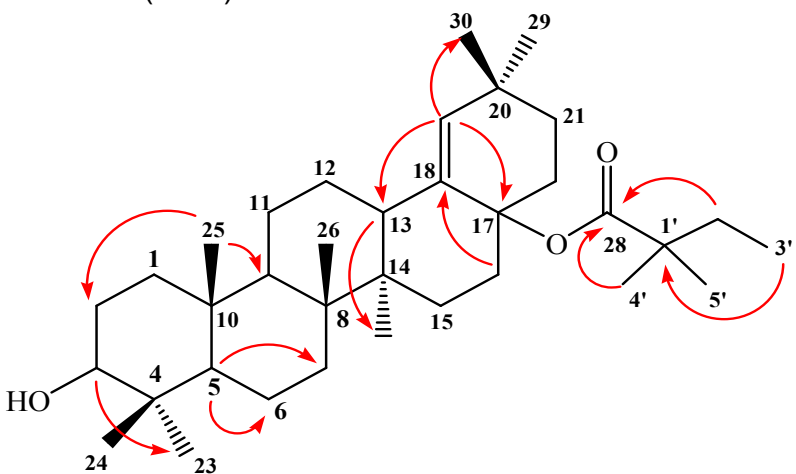

Figure 1: Proposed structure with significant $\mathrm{HMBC}$ correlations

Table 2: ${ }^{1} \mathrm{H},{ }^{13} \mathrm{C}$ NMR, DEPT-135, COSY, HSQC and HMBC chemical shift data $\left(\mathrm{CDCl}_{3}, 400 \mathrm{MHz}\right)$

\begin{tabular}{|c|c|c|c|c|c|c|}
\hline C No. & $\delta_{c}\left({ }^{13} C-N M R\right)$ & $\delta_{c}($ DEPT-35) & $\delta_{H}$ & COSY & HMBC & HSQC \\
\hline 1 & 38.4 & 38.4 & $1.45(2 \mathrm{H}, m)$ & $\mathrm{H}_{1} \leftrightarrow \mathrm{H}_{2}$ & $\mathrm{H}_{1} \rightarrow \mathrm{C}_{3}$ & - \\
\hline 2 & 27.7 & 27.7 & $1.60(2 \mathrm{H}, m)$ & - & - & - \\
\hline 3 & 79.0 & 79.0 & $3.20(1 \mathrm{H}, d d)$ & - & - & $\mathrm{H}_{3} \rightarrow \mathrm{C}_{3}$ \\
\hline 4 & 39.3 & - & - & - & & - \\
\hline 5 & 55.2 & 55.2 & $0.87(1 \mathrm{H}, m)^{*}$ & $\mathrm{H}_{5} \leftrightarrow \mathrm{H}_{6,24}$ & $\mathrm{H}_{5} \rightarrow \mathrm{C}_{4}$ & $\mathrm{H}_{5} \rightarrow \mathrm{C}_{5}$ \\
\hline 6 & 21.5 & 21.5 & $1.20(2 \mathrm{H}, m)$ & - & $\mathrm{H}_{6} \rightarrow \mathrm{C}_{5}$ & - \\
\hline 7 & 32.6 & 32.6 & $2.30(2 \mathrm{H}, m)^{*}$ & - & & - \\
\hline 8 & 38.7 & - & - & - & - & - \\
\hline 9 & 46.5 & 46.5 & $1.54(1 \mathrm{H}, m)^{*}$ & $\mathrm{H}_{9} \leftrightarrow \mathrm{H}_{11}$ & $\mathrm{H}_{9} \rightarrow \mathrm{C}_{1}$ & $\mathrm{H}_{9} \rightarrow \mathrm{C}_{9}$ \\
\hline 10 & 37.1 & - & - & - & - & - \\
\hline 11 & 22.9 & 22.9 & $1.65(2 \mathrm{H}, m)^{*}$ & - & & - \\
\hline 12 & 41.6 & 41.6 & $1.56(2 \mathrm{H}, m)^{*}$ & $\mathrm{H}_{12} \leftrightarrow \mathrm{H}_{13}$ & & - \\
\hline 13 & 45.9 & 45.9 & $2.00(1 \mathrm{H}, d)$ & - & & $\mathrm{H}_{13} \rightarrow \mathrm{C}_{13}$ \\
\hline 14 & 42.1 & - & - & - & - & - \\
\hline 15 & 27.1 & 27.1 & $2.15(2 \mathrm{H}, t)^{\star}$ & - & & - \\
\hline 16 & 18.3 & 18.3 & $1.80(2 \mathrm{H}, d t)^{*}$ & - & & - \\
\hline 17 & 76.7 & - & - & - & - & - \\
\hline 18 & 143.6 & - & - & - & - & - \\
\hline 19 & 122.5 & 122.6 & $5.30(1 \mathrm{H}, \mathrm{s})$ & - & $\mathrm{H}_{19} \rightarrow \mathrm{C}_{13,17}$ & $\mathrm{H}_{19} \rightarrow \mathrm{C}_{19}$ \\
\hline 20 & 30.7 & - & - & - & - & - \\
\hline 21 & 32.4 & 32.4 & $1.46(2 \mathrm{H}, m)^{*}$ & - & & - \\
\hline 22 & 33.8 & 33.8 & $1.55(2 \mathrm{H}, m)^{*}$ & - & $\mathrm{H}_{22} \rightarrow \mathrm{C}_{20}$ & - \\
\hline 23 & 15.3 & 15.3 & $1.05(3 \mathrm{H}, \mathrm{s})$ & - & & \\
\hline 24 & 16.9 & 16.91 & $0.95(3 \mathrm{H}, \mathrm{s})$ & - & & - \\
\hline 25 & 28.1 & 28.1 & $0.85(3 \mathrm{H}, \mathrm{s})$ & - & & $\mathrm{H}_{25} \rightarrow \mathrm{C}_{25}$ \\
\hline 26 & 17.1 & 17.1 & $0.65(3 \mathrm{H}, s)$ & - & & - \\
\hline 27 & 25.9 & 25.9 & $1.15(3 \mathrm{H}, s)$ & - & & $\mathrm{H}_{27} \rightarrow \mathrm{C}_{27}$ \\
\hline 28 & 183.8 & - & - & - & - & - \\
\hline 29 & 33.1 & 33.1 & $1.10(3 \mathrm{H}, s)$ & - & $\mathrm{H}_{29} \rightarrow \mathrm{C}_{20}$ & - \\
\hline 30 & 33.1 & 23.1 & $2.80(3 \mathrm{H}, s)$ & - & $\mathrm{H}_{30} \rightarrow \mathrm{C}_{19}$ & - \\
\hline 1 ' & 47.6 & - & - & - & - & - \\
\hline 2' & 36.1 & 36.1 & $2.10(2 \mathrm{H}, \mathrm{s})$ & $\mathrm{H}_{2} \leftrightarrow \mathrm{H}_{3}$ & $\mathrm{H}_{2}, \rightarrow \mathrm{C}_{1^{\prime}, 3^{\prime}}$ & - \\
\hline $3^{\prime}$ & 15.5 & 15.5 & $1.75(3 \mathrm{H}, t)$ & - & $\mathrm{H}_{3^{\prime}} \rightarrow \mathrm{C}_{2}$ & - \\
\hline $4^{\prime}$ & 23.4 & 23.4 & $0.79(3 \mathrm{H}, \mathrm{s})$ & - & $\mathrm{H}_{4^{\prime}} \rightarrow \mathrm{C}_{2}$ & - \\
\hline $5^{\prime}$ & 23.4 & 23.4 & $1.00(3 \mathrm{H}, \mathrm{s})$ & - & $\mathrm{H}_{5^{\prime}} \rightarrow \mathrm{C}_{2^{\prime}, 1^{\prime}}$ & - \\
\hline
\end{tabular}




\section{CONCLUSIONS}

The present work conducted on the methanol root extract of Lantana camara revealed the presence of terpenes, flavonoids, saponins and absence of anthraquinone, alkaloids and tannins. The traditional use of the plant may be attributed to its high content of terpenes, flavonoids and saponins. Despite the wide medicinal use of the genus Lantana in both Ethiopia and other parts of the world, to the best of our knowledge, there is no earlier phytochemical analysis work done on $L$. camara from Ethiopian flora. Thus, this work is expected to fill this gap. Apart from the phytochemical screening of the methanol root extract, isolation and NMR characterization of one olean-18-ene type triterpene was successfully achieved. As this work is one of the few attempts to phytochemically analyze the polar extracts of the plant, further work is recommended on polar fractions and extracts of the root and leaf of the plant so as to identify more novel and bioactive compounds in support of its traditional use.

\section{Conflict of Interest}

We declare that we have no conflict of interest.

\section{Acknowledgement}

We are grateful to Dr. Ensermu Kelbessa and staff members of the National Herbarium of Ethiopia, Addis Ababa University, for identification of the plant material. Prof. Ermias Dagne, Department of Chemistry, Addis Ababa University is duly acknowledged for allowing us to use $400 \mathrm{MHz}$ NMR spectrometer. We also extend special thanks to workers of Ethiopian Pharmaceuticals Manufacturing Factory (EPHARM) for access to IR spectrophotometer.

\section{Supplementary Data}

Online version of supplementary data associated with this article can be found along with the article for further reference.

\section{REFERENCES}

Chiang, L.C., Chiang W., Chang M.Y., Ng L.T., Lin C.C. (2003). Antileukemic activity of selected natural products in Taiwan. American Journal of Chinese Medicine 31(1):37-46

Debjyoti, D. (1995). Biochemistry $8^{\text {th }}$ Ed., Academic publishers, Kolkata, p 39.

Farnsworth, N.R. (1996). Phytochemical screening of the biologically active compounds from higher plants. Journal Pharmaceutical Sciences 55:227-276.

Ganjewala, D., and Dipita, B. (2009). Effect of leaf positions on total phenolics, flavonoids and proantho-cyanidins content and Antioxidant Activities in Lantana camara. Journal of Scientific Research 2:363-369.

Ghisalberti, E.L. (2000). Lantana camara (Verbenceae). Fitoterapia 71: 467-486.

Hua, S., Wei-Shuo, F., Wen-Zhao, W., Chun, H., (2006). Structure-activity relationships of oleanane- and ursanetype triterpenoids. Botanical Studies 47: 339-368.
Johns, S.R., Lamberton, J.A., Morton, T.C., Suares, H., Willing, R.I. (1983a). Triterpenes of Lantana tiliaefolia. 24Hydroxy-3-oxours-12-en-28-oic acid, a new triterpene. Australian Journal of Chemistry 36: 2537-2547.

Johns, S.R., Lamberton, J.A., Morton, T.C., Suares, H., Willing, R.I. (1983b). 22ß-[(S)-2-Methylbutanoyloxy]-3oxoolean-12-en-28-oic acid, a new constituent of Lantana camara. Australian Journal of Chemistry 36: 1895-1902.

Leak, S.G.A. (1999).Tsetse biology and ecology, their role in the epidemiology and control of trypanosomosis. CAB International, Wallingford, UK.

Mesfin, F., Demissew, S., Teklehaymanot, T. (2009). An ethnobotanical study of medicinal plants in Wonago Woreda. Journal of Ethnobiology and Ethnomedicine $5(28): 1-18$.

Nayak, B.S., Raju, S.S., and Ramsubhag, A. (2008). Investigation of wound healing activity of Lantana camara in Sprague dewily rats using a burn wound model. International Journal of Applied Research in Natural Products 1: 15-19.

Nagao, T., Abe, F., Kinjo, J. (2002). Antiproliferative constituents in plants: Flavones from the leaves of Lantana montevidensis Briq. and consideration of structural relationship. Biochemical Pharmaceutical Bulletin 25: 875-879.

Rajakaruna, N., Harris, C.S., Towers, G.H.N. (2002). Antimicrobial activity of plants collected from serpentine outcrops in Sri Lanka. Pharmaceutical Biology 40:235244.

Rios, M.Y., Salinas, D., Villarreal, M.L. (2001). Cytotoxic Activity of Moronic Acid and Identification of the New Triterpene 3,4-seco-Olean-18-ene-3,28-dioic Acid from Phoradendron reichenbachianum, Planta Medica 67: 443446.

Ross, I.A. (1999). Medicinal plants of the world: Chemical composition, traditional and modern medical uses. Totowa, New Jersey Human Press 2: 487-490.

Sankaran, K.V. (2007). Lantana camara. Invasive Species Fact Sheet. Asia-Pacific Forest Invasive Species Network, Food and Agricultural Organization of the United Nations (FAO).

Singh, S.K, Trpphathi, V.J., Singh, R.H. (1991). A new pentacyclic triterpene acid from Lantana indica. Journal of Natural Products 54(3):755-758.

Singh, S.K, Triphathi, V.J., and Singh, R.H. (1990). 3ß, 24Dihydroxyolean-12-en-28-oic acid, apentacyclic triterpene acid from Lantana indica. Phytochemistry 29(10):33603362.

Sofowora, A. (1982). Historical review of traditional medicine. In, medicinal plants and traditional medicine in Africa. John wily and Sons Ltd., Chichester, USA, 9-12.

Tripathi, A.K., Shukla, B.N. (2002). Antifungal activity of some plant extracts against Fusarium oxysporum sp. causing wilt of linseed. Journal of Mycology and Plant Pathology 32: 266-267. 


\title{
Phytochemical Screening and Characterization of Olean-18-ene Type Triterpeniod from the Roots of Lantana camara
}

\author{
Kebede Taye ${ }^{1^{*}}$, Kibret Fikadu $^{2}$, Fikre Mammo $^{2}$ and Milkyas Endale ${ }^{2^{*}}$ \\ ${ }^{1}$ Department of Chemistry, College of Natural and Computational Sciences, Mekelle University, \\ P.O. Box: 231, Mekelle, Ethiopia \\ ${ }^{2}$ Department of Chemistry, College of Natural and Computational Science, Hawassa University, \\ P.O. Box: 05, Hawassa, Ethiopia
}

\begin{tabular}{|c|c|}
\hline & Article Information \\
\hline \multirow{3}{*}{$\begin{array}{l}\text { Lantana camara, commonly called wild or red sage or sleeper weed is the most } \\
\text { widely spread species of the genus Lantana traditionally used to treat various } \\
\text { diseases such as diarrhea, fever, and stomachache. It has also been reported to } \\
\text { show antifungal, antiproliferative, insecticidal, antimicrobial and germicidal activity. } \\
\text { Phytochemical screening of the methanol extract revealed the presence of } \\
\text { flavanoids, terpenes, saponins and the absence of anthraquinones and alkaloids. } \\
\text { Silica gel column chromatographic separation of the methanol root extract yielded } \\
\text { an olean-18-ene type triterpene. Complete characterization of the isolated } \\
\text { compound was done using spectroscopic techniques (UV-Vis, IR, }{ }^{1} \mathrm{H}-\mathrm{NMR},{ }^{13} \mathrm{C}- \\
\text { NMR, DEPT-135, COSY, HMBC and HSQC). }\end{array}$} & $\begin{array}{l}\text { Article History: } \\
\text { Received : } 12-02-2015 \\
\text { Revised : 23-03-2015 } \\
\text { Accepted : } 24-03-2015\end{array}$ \\
\hline & $\begin{array}{l}\text { Keywords: } \\
\text { Lantana camara } \\
\text { Terpene } \\
\text { Olean-18-ene type triterpene }\end{array}$ \\
\hline & $\begin{array}{l}{ }^{*} \text { Corresponding Authors: } \\
\text { Milkyas Endale } \\
\text { E-Mail: milkyasendale@yahoo.com }\end{array}$ \\
\hline Copyright@2015 STAR Journal, Wollega University. All Rights Reserved. & $\begin{array}{l}\text { Kebede Taye } \\
\text { E-Mail: kebetila@gmail.com }\end{array}$ \\
\hline
\end{tabular}

Appendix 1: UV-Vis spectrum of compound 1

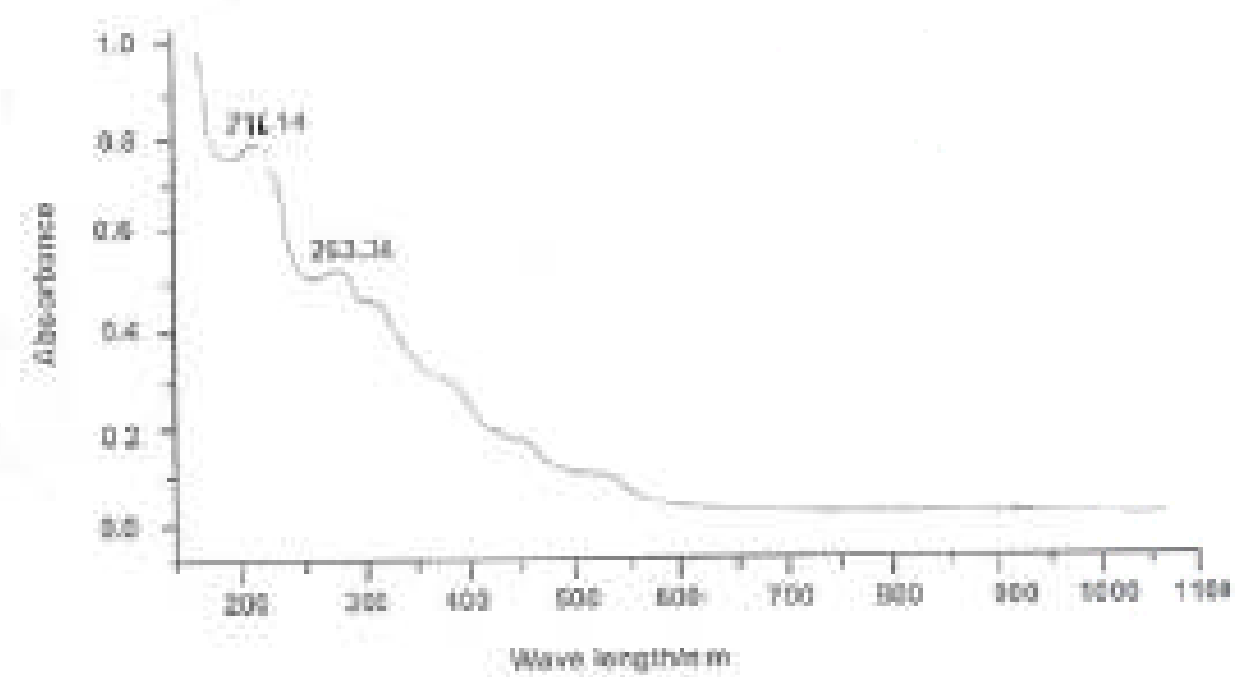



Appendix 2: IR spectrum of compound 1

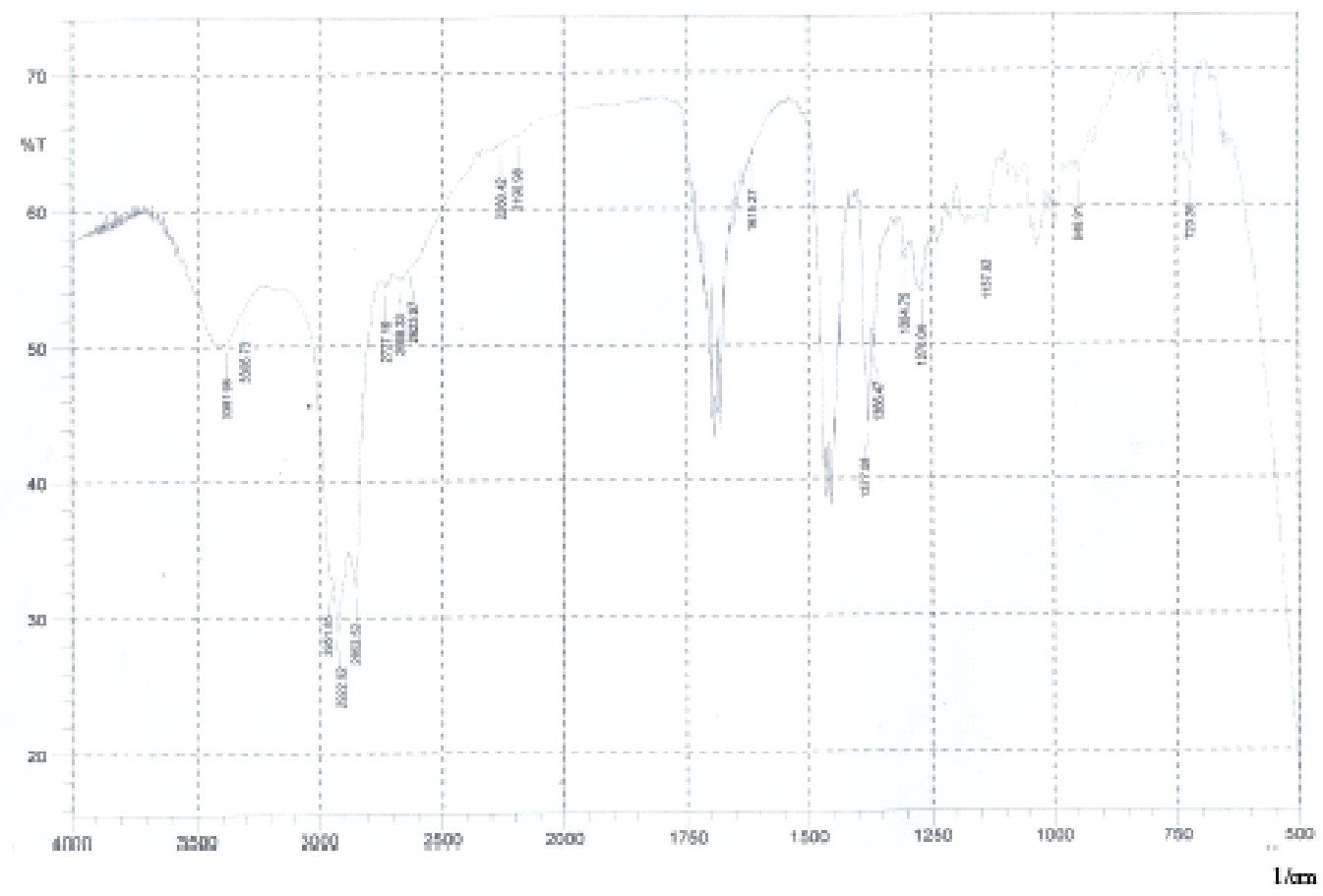

Appendix 3: ${ }^{1} \mathrm{H}$ NMR spectrum of compound 1

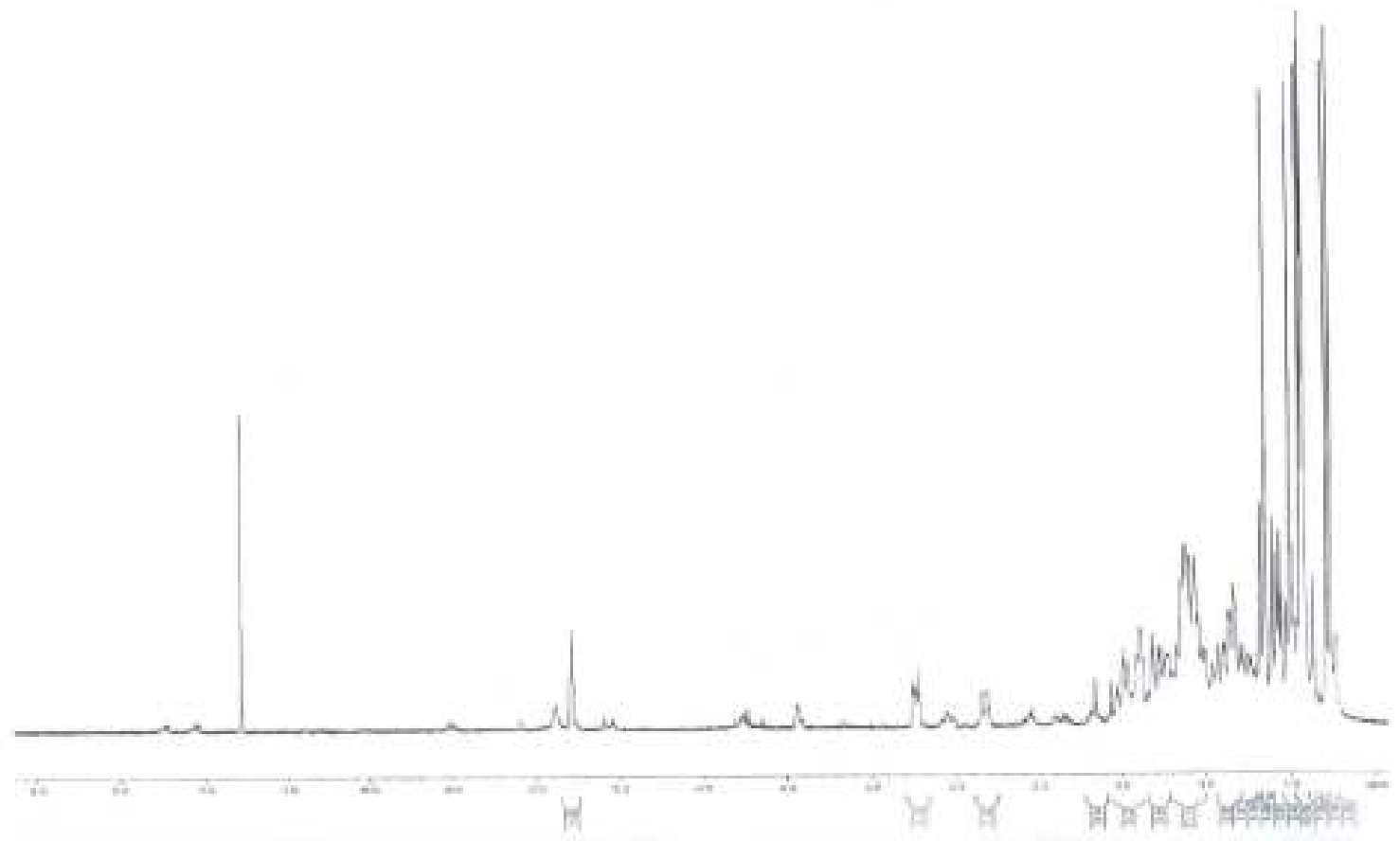



Appendix 4: ${ }^{13} \mathrm{C}$ NMR spectrum of compound 1

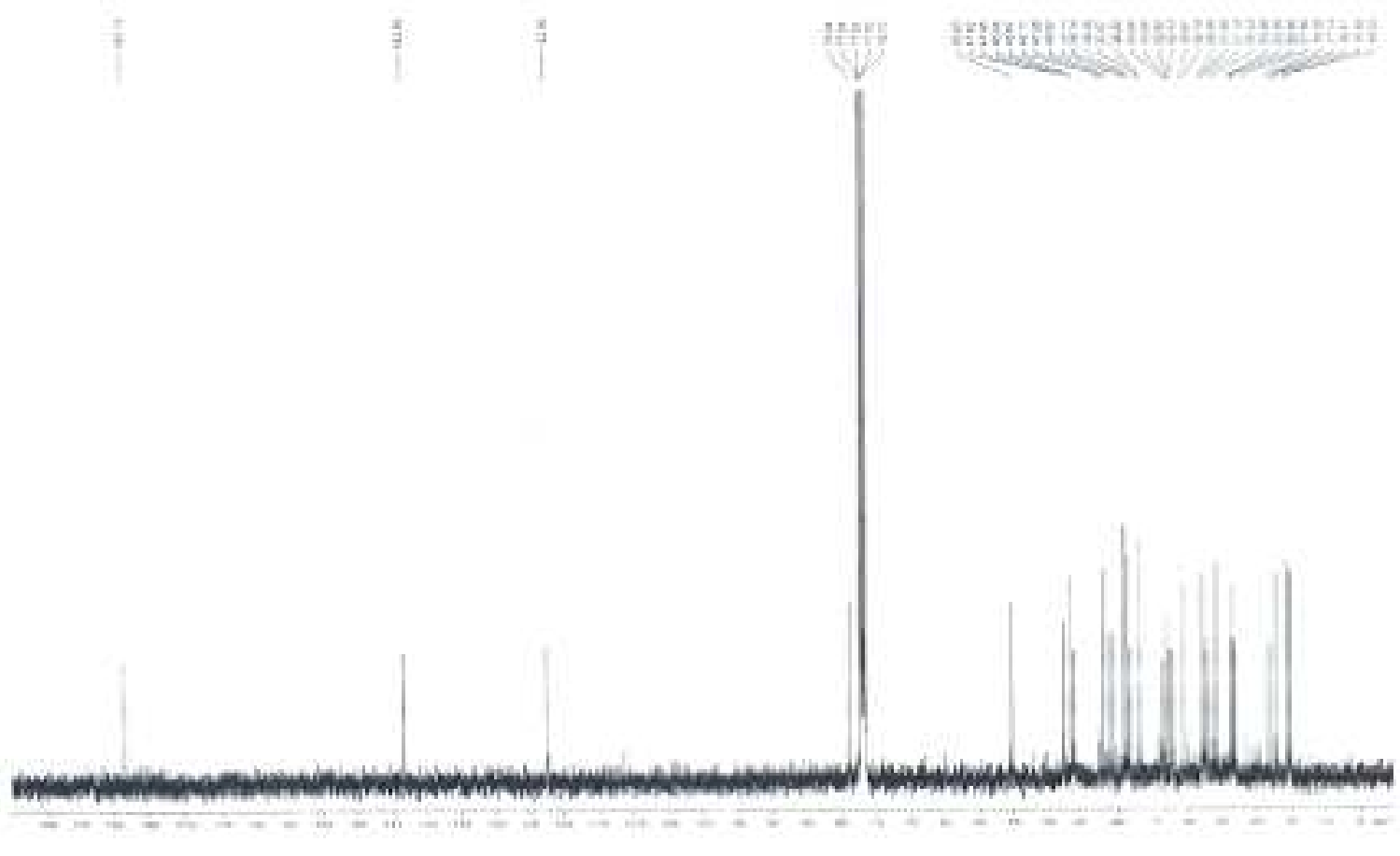

Appendix 5: DEPR-135 spectrum of Compound 1

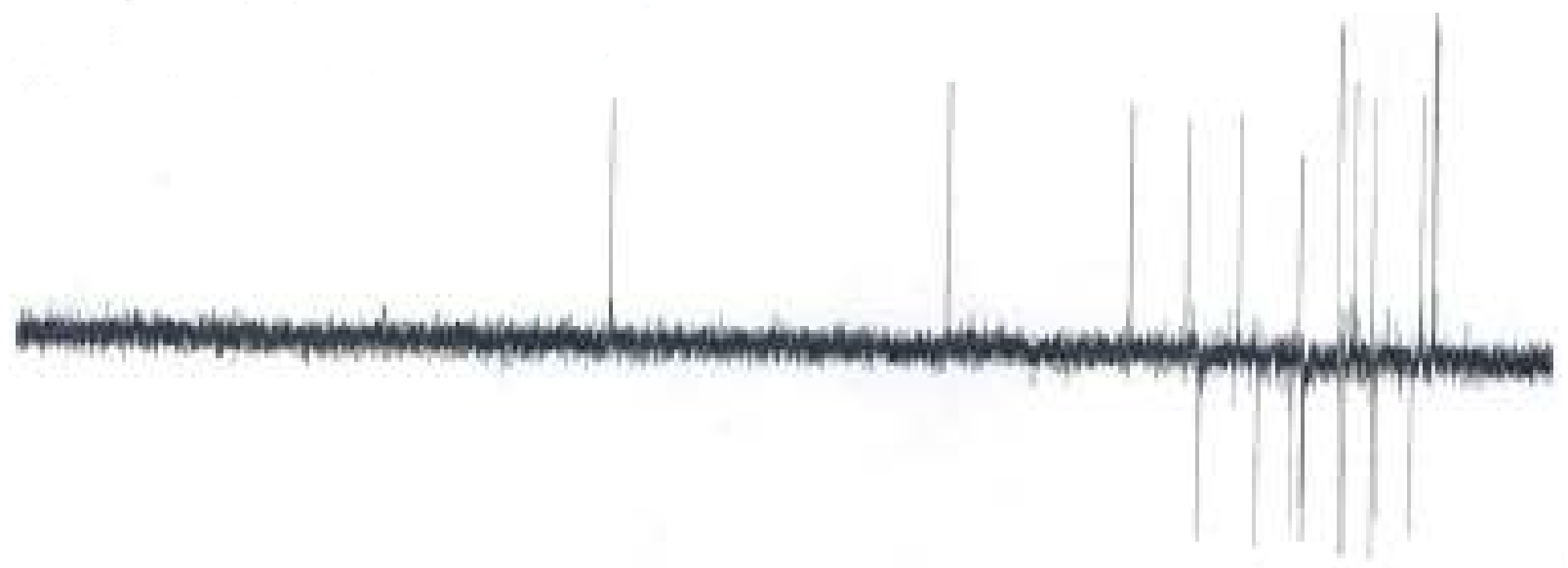




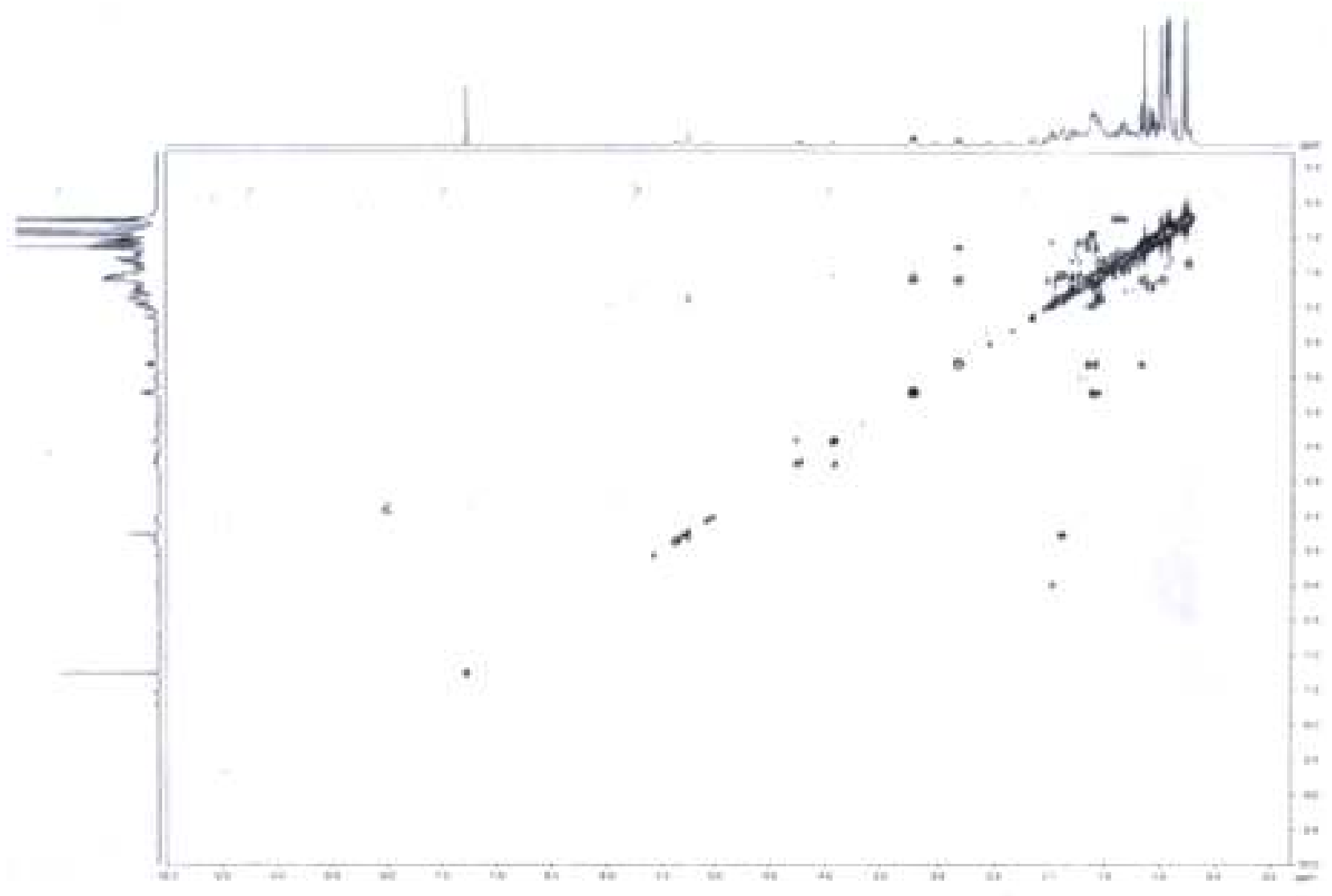

Appendix 7: gHMBC spectrum of compound 1

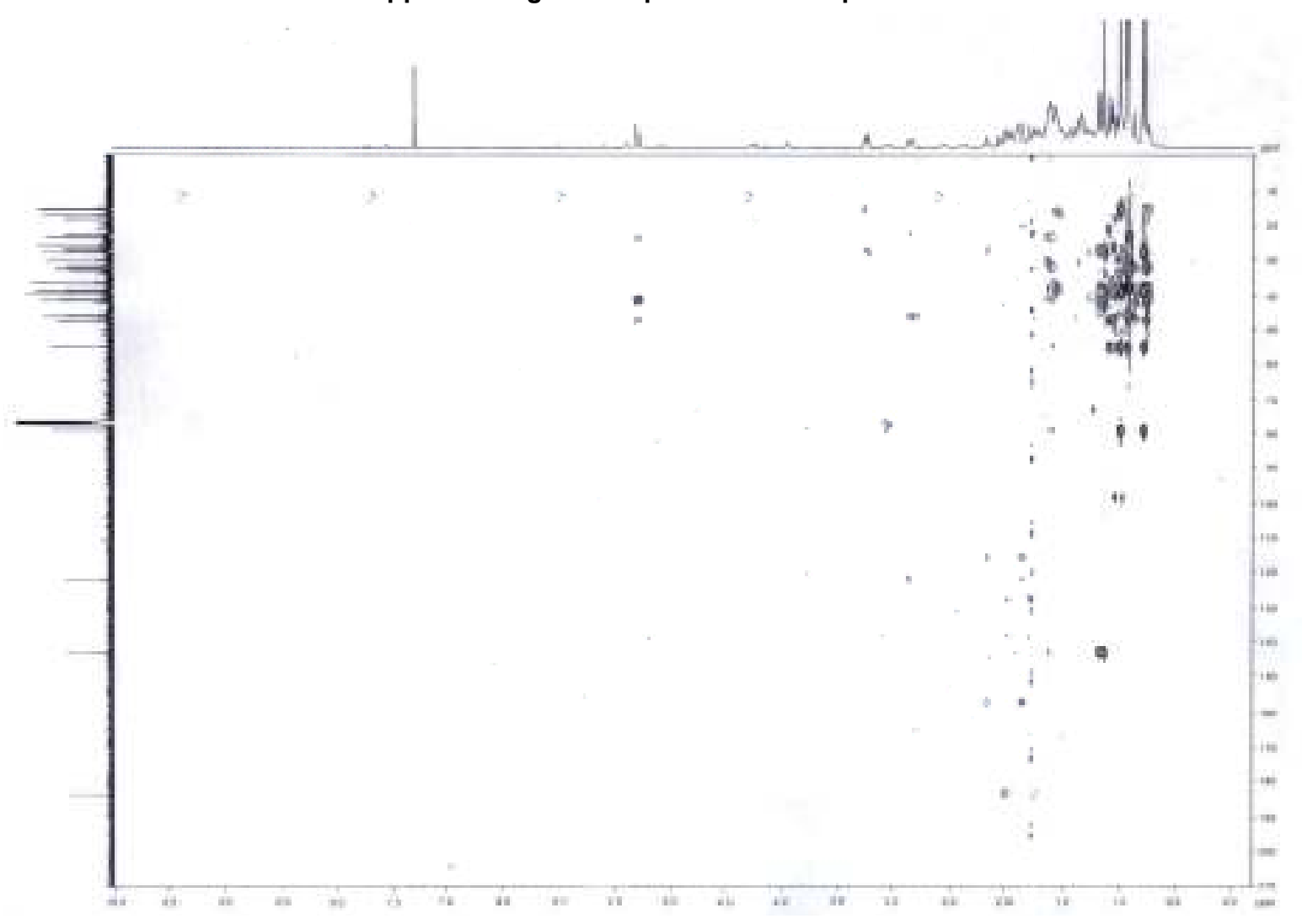

Appendix 8: HSQC spectrum of compound 1 
Sci. Technol. Arts Res. J., Jan-March 2015, 4(1): i-v

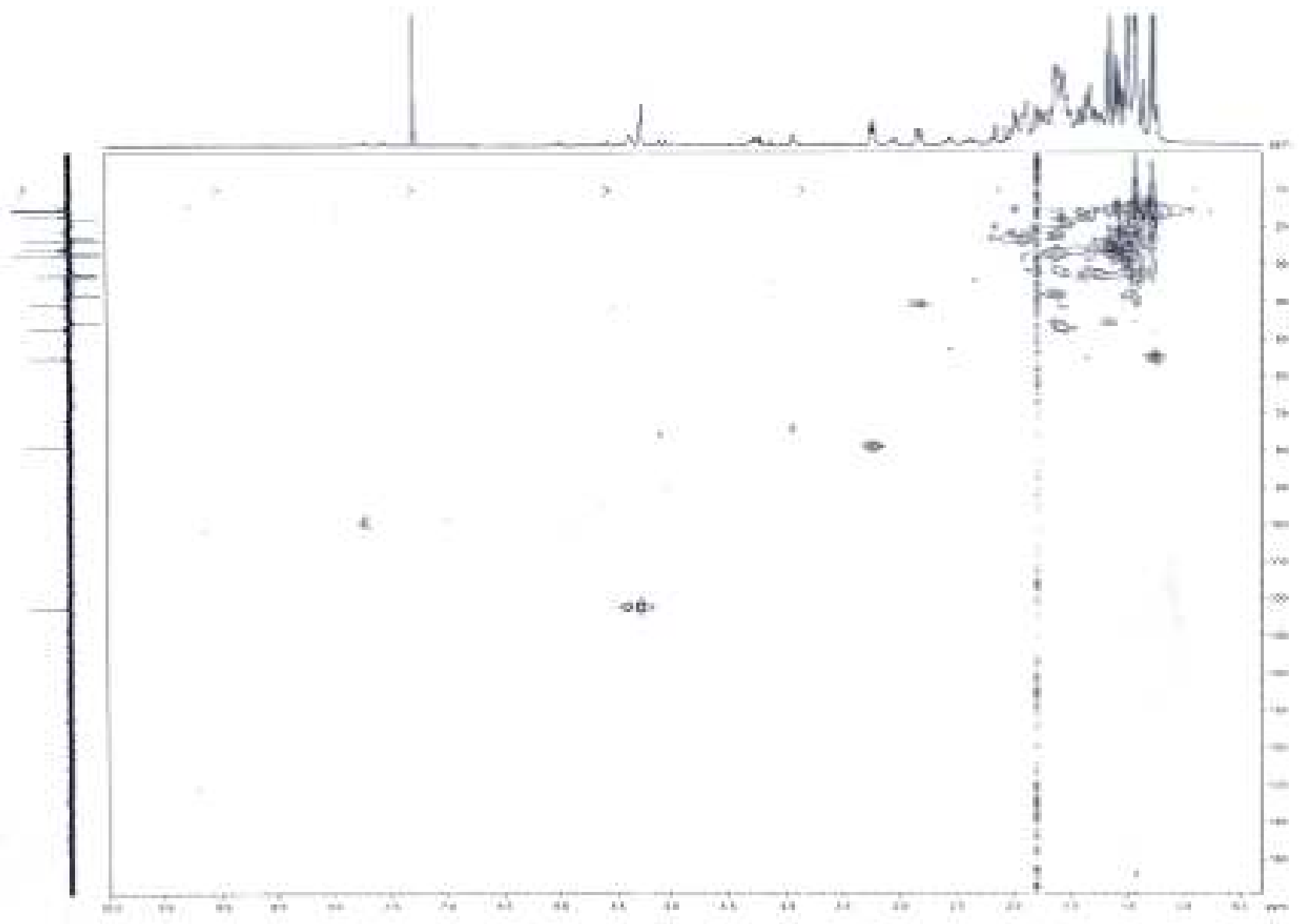

